\title{
Emerging Vehicle Control Using Embedded and Wireless in Transportation System
}

\author{
Abinaya.M ${ }^{1}$, Uthira Devi.R ${ }^{2}$, Yogeshwaran. $M^{3}$ \\ PG Student, ECE, Sri Eshwar College of Engineering, Coimbatore ${ }^{1}$ \\ Assistant Professor, ECE, Sri Eshwar College of Engineering, Coimbatore ${ }^{2}$
}

\begin{abstract}
Vehicle security and control is a more challenging process in day today life. Almost all people are having their own vehicle hence vehicle security and control becomes very essential. The need for the proposed system is to provide security to the vehicle by engine locking system and to provide enhancement to human life through accident detection, lane detection and by detecting the driver's fatigue. This technique prevents the vehicle from accessing by the unauthorized person and finds the location of accident along with driver's psychic behavior to provide $90 \%$ of human life enhancement. This system describes a real time safety prototype control for a vehicle.
\end{abstract}

Keywords: microcontroller, sensors, GSM, GPS, display, alerting system

\section{INTRODUCTION}

In recent years, a large numbers of vehicles are owned and being used daily by large numbers of people. The biggest problem regarding the increased use of private transport is the rising number of fatalities that are occurring as a consequence of accidents on the roads; the associated expense and related dangers have been recognized as a serious problem that is being confronted by modern society. Based on statistics report, $95 \%$ of traffic accidents are related to human factors, while approximately $70 \%$ are directly related to human errors. Hence driving is a process that requires of the driver enough skill to adapt to environmental changes. Obviously, everyone who uses our road system is concerned about safety.

The contribution to the overall health and safety of your community made by roadway safety is not necessarily known by everyone. First, the three major components of highway safety are driver's psychic behavior, vehicle security, and roadway safety. Roadway safety refers to overall highway operating conditions, roadside objects, bridges, and intersections. The personal and economic costs of highway crashes to our citizens and communities are enormous.

\section{SURVEY:}

\section{RELATED WORK}

In [1], Ramani and Valarmathy have proposed a vehicle tracking system which is an electronic device, installed in a vehicle to track them. This device is designed for vehicle tracking system that works using GPS and GSM technology. This system is built based on embedded system, used for tracking the position of any vehicle using Global Positioning System (GPS) and Global system for mobile communication (GSM). In [2],

Zhang Wen and Jiang Meng proposed a method to explores location solution, map matching and data compress that are associated with the positioning and it shows a program flowchart and predicts the trend of the vehicle location system in the future.
In [3], Sonika and Jaishree introduced a Intelligent Transport System(ITS) to identify the accident with the location which is immediately sent to the server, so that nearby hospital is found and emergency vehicle is sent to the accident zone.

In [4], Saif Al-Sultan and Hussien Zedan introduced a system for a real time safety that detects the driver condition and adjusts the speed of the vehicle. Sensors use Psychological signals to detect the driver's behavior. When the driver is in abnormal condition first a warning signal is issued to alert the driver and braking will be applied if he continues driving.

In [5], Pau Munoz- Benavent proposed a system of Automation of a Neighborhood Electric Vehicle (NEV) and the embedded distributed architecture for implementing an Advanced Driving Assistance System (ADAS) with haptic, visual, and audio feedback in order to improve safety with the feature of collision avoidance and motion planning.

In [6], Ramya and Karthick proposed a system that provides vehicle a cabin safety and security. This method monitors the level of the toxic gases within the vehicle and provides alert information during the dangerous situations.

IR Sensor is used to detect the static obstacle in front of the vehicle and the vehicle stopped if any obstacle detected.

This is to avoid accidents due to collision of vehicles with any static obstacles.

\section{OVERVIEW OF AN EXISTING SYSTEM}

Technological approaches for monitoring and detecting vehicle and controlling the vehicle continue to emerge and many are now in the development.

Previous studies have reviewed available detection and prediction technologies and methodologies. 
A method using GPS to monitor the vehicle is the most popular method. Previous technologies which are described above have certain drawbacks such as

* Failure of keypad security system

* Unable to hear the alarm sound when the vehicle is parked in the parking area

* In case of unauthorized use, ignition control is used to stop the vehicle but the unauthorized person get escaped

* Accident Identification and Driver behavior are only proposed but not implemented in real time.

* All the application which are proposed are implemented as a single application in the real time.

\section{PROPOSED WORK}

Aim of the proposed work, is to develop an active safety system or reducing the number of automobiles accidents due to reduced vigilance.

$>$ A novel method of vehicle tracking and locking system is used to track the theft vehicle by using GPS and GSM technology. The system will be in sleeping mode when the vehicle is handled by the owner or authorized person otherwise the system goes to active mode. The mode of operation is changed by in person or remotely.

In case of theft, an SMS is sent to the controller and the controller issues the control signals to the engine motor along with the location of the vehicle to the owner or authorized person using GPS. Engine motor speeds are gradually decreased and come to the off and all the doors are locked.

To open the door or restart the engine, authorized person needs to enter the code so that the thief cannot get away from the car.

$>$ Fuel theft are prevented using fuel sensor which is a variable resistor placed in the fuel tank.

$>$ Intelligent accident identification system provides the location of the accident to the nearby hospital so that an emergency vehicle reaches the place as soon as possible.

$>$ Sensors are used to detect the driver's psychic behavior since most of the accidents are occurred due to the driver's fatigue condition and his/her drowsiness.

> Obstacle detection system is used to stop the vehicle when an obstacle is found infront of the vehicle using IR sensor.

\section{SYSTEM ARCHITECTURE}

To enhance the vehicle security and human life enhancement by means of ignition control, fuel leakage, accident identification and prevention, driver fatigue, obstacle detection, and lane detection with parking motors.

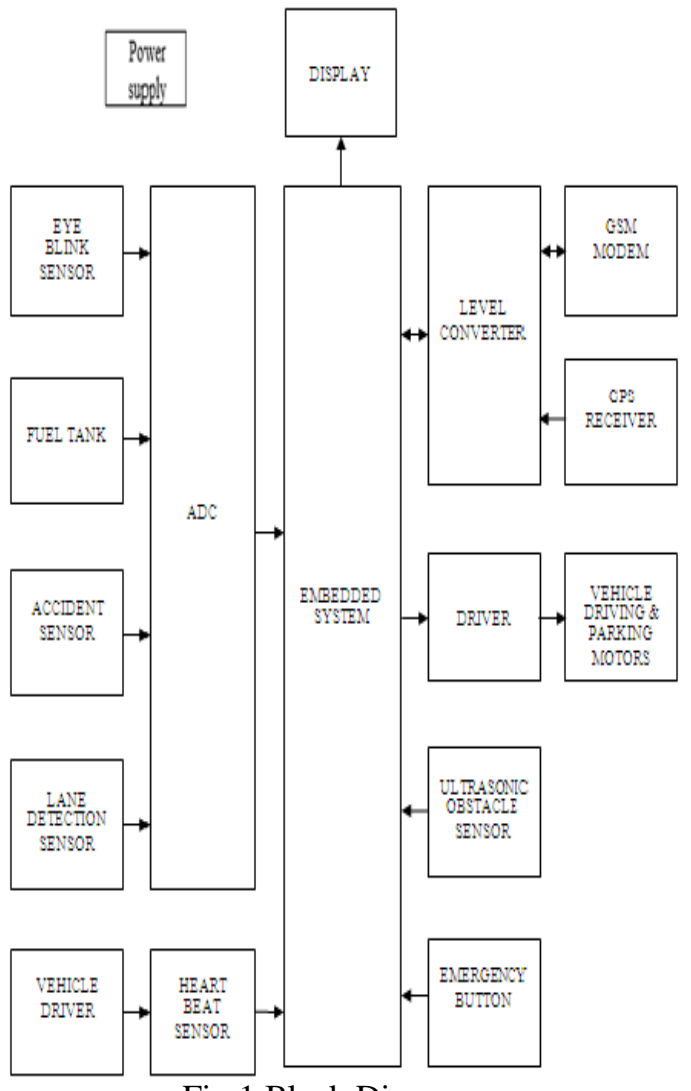

Fig 1:Block Diagram

Fig 1 represents the block diagram of the proposed system. Vehicle security is enhanced by ignition control. Fuel leakage can be prevented by monitoring the fuel level in fuel tank. Accident identification system provides the location at which accident occurs. Driver fatigue system provides information about drivers heart beat and eye blink rate which prevent accident because of the drowsiness or drunk and drive by the driver. A obstacle detection system helps in stopping the vehicle when an obstacle is detected using IR sensor. Vehicle management provides efficient vehicle parking system a obstacle detection system helps in stopping the vehicle when an obstacle is detected using IR sensor.

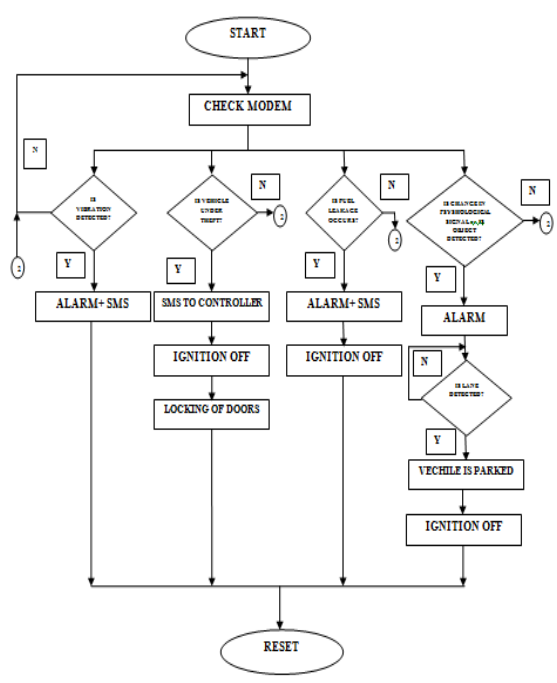

Fig 2: Flow Diagram 


\section{A) PIC MICROCONTROLLER: 16F877A}

PIC is a family of Harvard architecture micro controllers. It is derived from the PIC1640 which is originally developed by General Instrument's Microelectronics Division. PIC refers to "Peripheral Interface Controller". PIC controllers plays its prominent role in electronics industry because of its low cost, low power consumption, wide availability, suitable for all the applications, free development tools, and serial programming (and reprogramming with flash memory) capability.

\section{B) GSM TECHNOLOGY}

The GSM modem is a specialized type of modem which accepts a SIM card operates on a subscriber's mobile number. GSM is a cellular network, which means that mobile phones connect to it by searching for cells in the nearby area. It is a cellular phone without display.

\section{C) GPS TECHNOLOGY}

Global Positioning System. A network of satellites that continuously transmit coded information which makes it possible to precisely identify locations on earth by measuring distance from the satellites. GPS has a variety of applications.

\section{D) SENSORS}

\section{EYE BLINK SENSOR:}

Vehicle accidents are most common if the driving is improper. Accidents occur in most of the factors if the driver is drowsy or if he is alcoholic. Once the sensor detects that the driver is unconscious while driving, then the vehicle is expected to detect the edge of the road and then stop.

\section{HEART BEAT SENSOR:}

The circuit is designed to measure the heart beat rate using IR transmitter and receiver. Both IR transmitter and receiver should be placed in a straight line to each other. Once the transmitter detects the decrease in heart beat rate immediately it sends information to IR receiver so that the controller receives the signal and vehicle is stopped in the nearby lane.

\section{ULTRASONIC SENSOR:}

Ultrasonic sensor is an obstacle sensing module is used to sense the object such that, accidents due to unwanted parking of the vehicles and collision with trees and other objects especially during the night time could be avoided.

\section{FUEL SENSOR:}

Fuel Sensor is material which is allowed to float over the fuel. This material is mechanically connected with the variable resistor. When there is a sudden change in the fuel level, the value of the variable resistor also will change accordingly. The sudden decrease in fuel level will decrease the resistance value indicating the fuel theft.

\section{VIBRATION SENSOR:}

The Piezoelectric effect is an effect in which energy is converted between mechanical and electrical forms. When a pressure (piezo means pressure in Greek) is applied to a polarized crystal, the resulting mechanical deformation results in an electrical charge. Piezoelectric microphones serve as a good example of this phenomenon. Microphones turn an acoustical pressure into a voltage. Alternatively, when an electrical charge is applied to a polarized crystal, the crystal undergoes a mechanical deformation which can in turn create an acoustical pressure.

\section{SIMULATION RESULTS}

The software simulation of the paper was done using PROTEUS software. The results are:

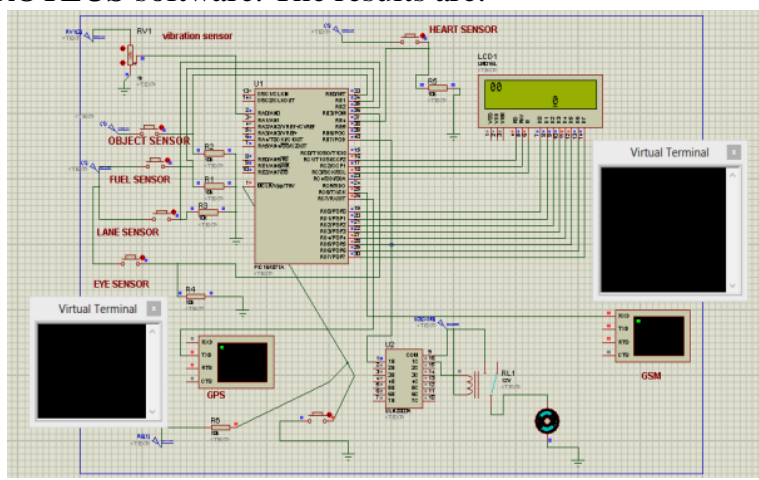

Fig 3: Simulation Results

The fig 3 implies the simulation under normal running condition.

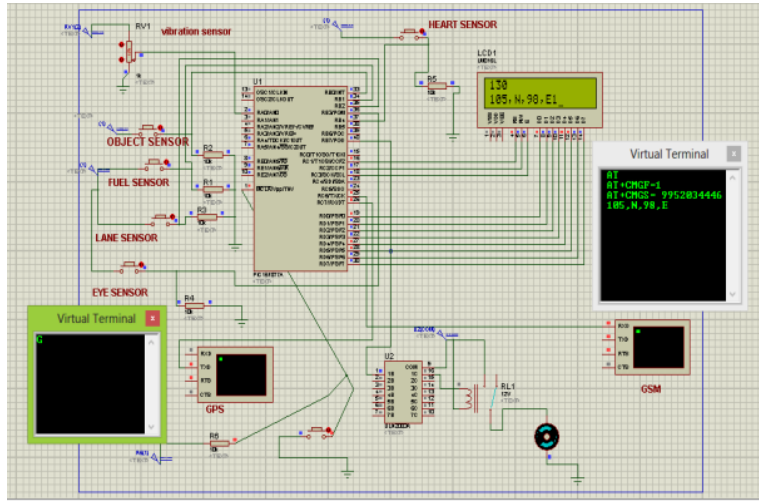

Fig 4: Simulation Result1

The fig 4 implies the simulation when the condition of the driver is abnormal and the accident has occurred.

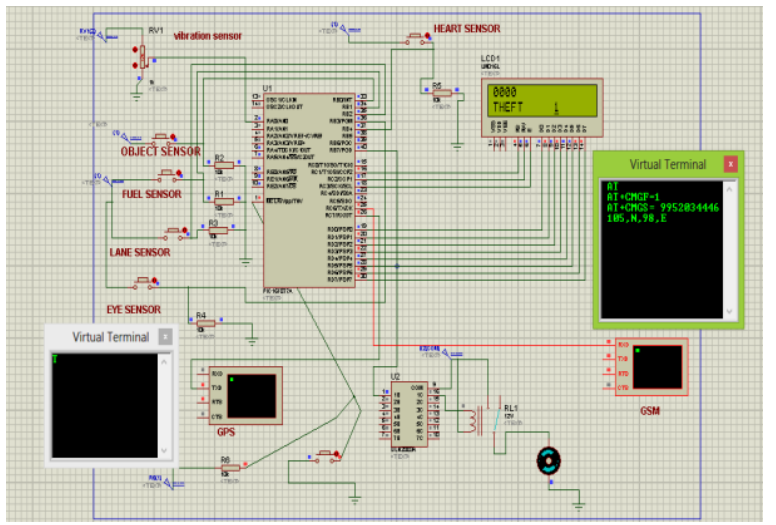

Fig 6: Simulation Result 2

The fig 6 implies the simulation result when the vehicle is under theft 
V. HARDWARE DESIGN

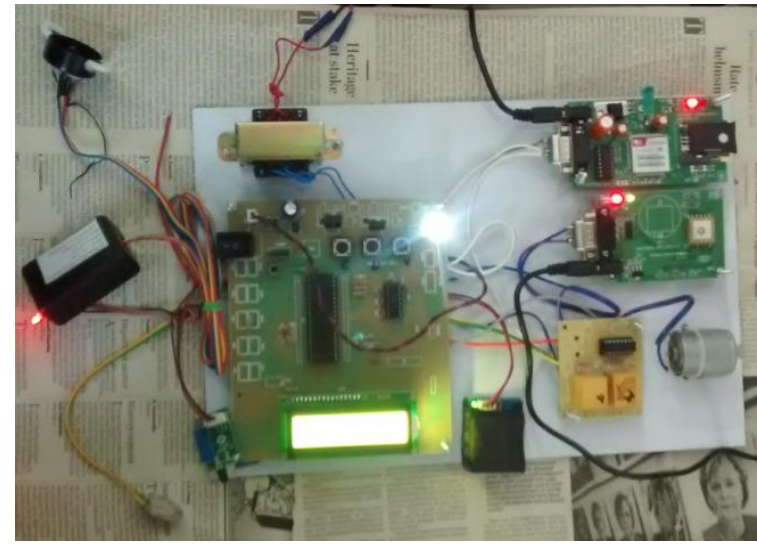

\section{CONCLUSION}

In this paper, we have proposed a novel method of vehicle tracking and locking which is used to track the theft vehicle using GPS and GSM technology. The system is put into the sleeping mode when the vehicle is handled by the owner or authorized persons; otherwise the system goes to the active mode. The mode of operations is changed by persons or remotely. When the vehicle theft is detected, the authorized person sends SMS to the micro controller, and the controller sends the control signals to stop the engine motor so that all the doors are locked. To open the doors or to restart the engine authorized person needs to enter the passwords. In this method, the vehicle can be easily tracked.

- Accident prevention is provided using eye blink sensor, heart beat sensor, accident sensor wherein the vehicle is stopped immediately and information is sent to the server.

- This system also involves obstacle detection along with lane detection for efficient vehicle parking management at emergency situation.

\section{REFERENCE}

[1] Ramani.R, Valarmathy.S, Dr. Suthanthira Vantiha, (2013), "Vehicle Tracking and Locking System Based on GSM and GPS", IJISA, Vol 9, pp 86-93.

[2] Zhang Wen, Jiang Meng. (2009), "Design of Vehicle Positioning System based on ARM", IEEE Vol 14.

[3] Sonika.S, Dr.K.Sathiyasekar, Jaishree.S, (2014), "Intelligent Accident Identification System using GPS, GSM modem", IJARCCE, Vol 3, Issue 2, pp 5487-5489

[4] Saif Al-Sultan, Ali H. Al-Bayatti and HussienZedan. (2014), "Context Aware Driver Behavior Detection System in Intelligent Transportation Systems" IEEE Vol 15.

[5] PauMuñoz-Benavent, LeopoldoArmesto, VicentGirbés, J. Ernesto Solanes, Juan Dols, Adolfo Munoz, and JosepTornero. (2013), "Advanced Driving Assistance Systems for an Electric Vehicle" AUSMT, Vol 2, No 2

[6] Ramya.V, Palaniappan.B, Karthick.K,. (2012), "Embedded Controller for Vehicle In-Front Obstacle Detection and Cabin Safety Alert System", IJCSIT, Vol4, Issue2, pp117-131

[7] Albert Alexe, Ezhilarasie.R. (2011), "Cloud Computing Based Vehicle Tracking Information Systems”, ISSN: 2229 - 4333(Print) | ISSN: 0976 - 8491 (Online) IJCST Vol. 2, Issue 1.

[8] Asaad M. Al-Hindawi.J, IbraheemTalib. (2010), "Experimentally Evaluation of GPS/GSM Based System Design", Journal of Electronic Systems Vol 2, NO 2.

[9] Chen, H., Chiang, Y. Chang, F., H. Wang, H. (2010), "Toward Real-Time Precise Point Positioning: Differential GPS Based on
IGS Ultra Rapid Product", SICE Annual Conference, the Grand Hotel, Taipei, Taiwan August 18-21.

[10] KunalMaurya, Mandeep Singh, Neelu Jain. (2010), "Real Time Vehicle Tracking System using GSM and GPS Technology- An Anti-theft Tracking System," International Journal of Electronics and Computer Science Engineering. ISSN 2277-1956/V1N31103-1107

[11] VikramKulkarni, ViswaprakashBabu,.(2010), "Embedded smart car security system on face detection", special issue of IJCCT, ISSN(Online):2231-0371, ISSN(Print):0975-7449,vol-3, issue-1

[12] Kai-Tai Song, Chih-Chieh Yang, of National Chiao Tung University, Taiwan. (2009), "Front Vehicle Tracking Using Scene Analysis", Proceedings of the IEEE International Conference on Mechatronics \& Automation.

[13] Chen Peijiang, Jiang Xuehua, (2008) "Design and Implementation of Remote monitoring system based on GSM", vol.42, pp.167175 .

\section{BIOGRAPHY}

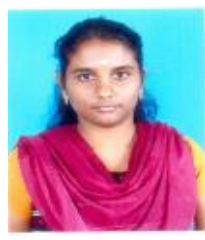

M.Abinaya completed her B.E in Electronics and Communication Engineering from Tamil Nadu College of Engineering and currently pursuing M.E in Applied Electronics at Sri Eshwar College of Engineering. Her area of research is in the field of Transportation system. She had presented quite number of papers in International and National conference. She is an IEEE member. 